\title{
Digital scholarship as a learning center in the library Building relationships and educational initiatives
}

A co-conveners of the newly formed ACRL Digital Scholarship Center (DSC) Interest Group, we organized a 2016 ALA Annual Conference program, Starting from Scratch: Build Your Digital Scholarship Center Program, which emerged from what we learned after conducting two webinars, a face-to-face meeting of our members, and a survey of existing digital scholarship centers. The program was based on presentations from three different digital scholarship center implementations, from the most basic at a four-year liberal arts college to a sophisticated technology hub at a large research university. The main takeaway from the ALA session resonated with the focus of the interest group: to share what we have learned along our journey and to emphasize that digital scholarship centers should not be limited to large research universities or those with extensive resources.

The DSC Interest Group currently serves 358 members, a testament to growth in this area. We meet in-person at the ALA Midwinter Meeting and ALA Annual Conference, hold online meetings in-between, moderate an email list, and post activities to our ALA Connect space. In 2016, two of our members facilitated a survey of digital scholarship centers to benchmark foundational information, including types of services offered, space, programming, and technology. ${ }^{1}$ We have been inspired by the ongoing work of Joan Lippincott and the Coalition for Networked Information (CNI). In May 2016, CNI partnered with the Association of Research Libraries (ARL) to facilitate a workshop, "Planning a Digital Scholarship Center: A CNI-ARL Workshop," and the corresponding report reminds us, "The work libraries are doing in digital scholarship is very deep, but more work remains."

Initial interest in our conversations has come from librarians looking to design and develop a digital scholarship center at their institutions, searching for inspiration and workable strategies from colleagues already taking a leadership role in centralizing and advancing institutional capacity for digital scholarship. There are many, sometimes competing, visions for what a digital scholarship center looks like-a hub for the digital humanities, experts to answer questions about data management, a maker space with 3-D printers, and much more. What works for one campus looks very different for another. The technol-

Merinda Kaye Hensley is digital scholarship liaison and instruction librarian at the University of Illinois at Urbana-Champaign, email:mhensle1@illinois.edu, and Steven J. Bell is associate university librarian for research and instruction at Temple University, email: bells@temple.edu

(ㄷ) 2017 Merinda Kaye Hensley and Steven J. Bell 
ogy in digital scholarship centers such as Arduino kits, laser cutters, virtual reality headsets, high-end scanners, visualization and video walls, and specialized software, provide an opportunity to build on the expertise of librarians, who are knowledgeable and passionate about sharing technology's connection to research but also willing to learn along with faculty and students as they explore possibilities presented by new models of digital scholarship. We have also come to realize how digital scholarship centers are more than cool technology. They are as much about hands-on learning as they are about conducting advanced conceptual research.

Since centers cannot wholly take on the responsibility of digital scholarship education, we must be willing to construct a network of collaborators across campus who have similar interests in leveraging new technologies and research methods to advance scholarship and learning at our institutions.

In this article we will share what we have learned along our journey as librarians who have worked directly in or closely with our digital scholarship center and believe that having a center is not limited to large research libraries or those with extensive resources.

\section{Where do digital scholarship centers stand today?}

Digital scholarship centers have been in motion for almost a decade, so it is reasonable at this point to ask: For those with established space and services, you've built your digital scholarship center, now what? In other words, have libraries been able to provide the kind of support, space, and services scholars need in order to envision and move digital scholarship projects forward? To our way of thinking digital scholarship exists as a verb and noun. In support of activities such as text analysis or data visualization, digital scholarship is an act of creation. When scholars perform these activities, the end product is an ob- ject for learning, analysis, or publication. The act of creating the visualization results in the production of a new digital map, an object that scholars may use for their own analysis. ${ }^{3}$ Most of us have been operating on the assumption that if we build it, students and faculty will come, but are the services we've imagined really what they need?

One of the questions we must ask as we assess our centers is, "What does it mean to be a digital scholar?" There is no agreement on a definition of digital scholarship and a scan of the literature exposes a wide variety of perspectives. In a 2014 essay for EDUCAUSE, Brian Sinclair points out, "In an age of visualization, analytics, big data, and new forms of online publishing, these central spaces can facilitate knowledge creation and transfer by connecting people, data, and technology in a shared collaborative space." ${ }^{4}$

To accomplish this goal, it could be argued librarians face a chicken-and-egg situation. On the one hand, we have been at the forefront of technological advances in scholarship and have conceptualized services around a wide variety of research needs for which the expertise of librarians is well-established and appropriate (e.g., data management). On the other hand, we are reacting to scholars' needs and in turn pushing our own expertise past traditional boundaries.

For example, most digital scholarship centers include a plethora of technology. While we don't need to learn all the skills to support all the technology, we should organize digital scholarship centers in such a way that creates connections between experts and novices, while providing space and opportunity for conversation. We should also be using our collaborative campus relationships to organize a network of experts for effective referrals. Furthermore, we should consistently reassess our service profile strategies based on our interactions with students and faculty, weighing our strengths against needs and 
paying close attention to the ways digital scholarship is evolving in order to help predict the types of support that will be needed in the future.

Over the past five years, the Scholarly Commons at the University of Illinois at Urbana-Champaign (UIUC) has been engaged in a discussion regarding how librarians can facilitate invitations to participate within research partnerships, especially during the idea phase, where we feel that our expertise could influence the planning process for digital scholarship. All too often we are in reaction mode, in part because faculty don't know what they need until they need it, and in part because libraries are in the middle of an overarching narrative shift about the ways in which librarians can help throughout the digital scholarship process. In a recent post to "The Impact Blog," hosted by the London School of Economics and Political Science, the authors propose the role of librarian as coinvestigator: "Imagine research librarians as equal partners in the research process, helping a scholar in any discipline to map existing knowledge gaps, identify emerging disciplinary crossovers before they even happen, and assist in the formulation and refinement of frontier research questions." 5

While librarians may have loads of ideas for how to design digital scholarship support and services, if those ideas clash with a scholars' workflow or goals for tenure and promotion, we failed. The question remains: How do we align our ideas and expertise to the digital scholarship needs of students and faculty? We argue the answer is centered on two alternative needs assessment approaches: relationship building and educational initiatives.

\section{Focus on building relationships}

Our initial advice to those taking next steps, whether you are starting or expanding a digital scholarship center, is to first identify needs by building relationships with faculty and students across the spectrum of disciplines as well as with campus partners. At Temple University Libraries, staff initially connected with the University's Center for Humanities to learn more about the type of digital scholarship projects of graduate students and faculty. The Libraries' digital initiatives team started an "office hours" program to offer consultations to digital scholars needing advice and support for text analysis, screen scraping, or visual data presentation. As interest grew, we tested the waters across campus by developing workshops to see if there was broader interest beyond the Center for Humanities. In return, librarians were invited to participate and learn more about digital scholarship from the scholars' perspective. We also hired graduate students to work on increasingly complex projects and assist other students. Taken together, these efforts laid the foundation for our digital scholarship center.

While there is no one correct path to developing digital scholarship services, starting small and building slowly is a strategy that may work for many institutions, particularly smaller colleges that need to avoid going all in on a project that may ultimately be unsustainable. To the extent possible, finding faculty that can serve as digital scholarship champions by setting a research agenda and encouraging other faculty to participate will contribute to a center's campus reputation. One path to sustainability is the faculty fellow position in the digital scholarship center. This may work well for institutions lacking the resources to reassign a librarian or to hire a full-time digital scholarship center coordinator. In exchange for course release, faculty conducting digital scholarship may be eager to take on the role of setting the center's research agenda and demonstrating to faculty and students the expertise libraries bring to the digital scholarship process.

\section{Focus on learning}

Educational initiatives at the heart of a digital scholarship center can also serve 
as an alternate form of needs assessment for better understanding digital scholarship needs. At UIUC, librarians have been experimenting with open workshops focused on advanced research and information management needs for almost a decade. ${ }^{6}$ The workshops cover topics beyond a typical instruction program and introduce scholars to topics related to data management and visualization, scholarly communication and publishing, and information management, etc. Most importantly, from a digital scholarship perspective and through a marketing lens, the workshops share a narrative to the campus about how libraries can assist with a wide variety of aspects of the research process, including the many approaches and tools of digital scholarship.

Attendance at workshops, seminars, brown bags, and other events often stimulate conversation directly related to the practical issues on a wide variety of digital scholarship topics. For example, when students self-select into a workshop, they often come with a question that may not be the sole purpose of the content presented, but they are searching for someone to talk to about the struggles they are facing in their research. This scenario opens opportunities for librarians to engage in a conversation and ask questions regarding the specifics of a digital scholarship project and to explore alignment between research needs and library capability. Workshops can also bring together scholars across disciplines, creating a room of diverse discussion leading to relationshipbuilding opportunities, where scholars may share their expertise with one another. In our experience, it is these relationships evolving over time that encourage faculty and students to invite librarians into the totality of the digital scholarship process, including grant-funded projects and research teams.

At the spring 2016 annual digital scholarship speaker series at UIUC, Ariel Waldman, founder of Spacehack.org, made an excellent point that resonates with the challenges scholars face in producing digital scholarship: as individuals, we don't need to be an expert to incorporate digital scholarship into research, rather we can learn just enough to get by in a specific situation or rely on an expert to guide us. ${ }^{7}$ The digital scholarship center serves a locus of experts and novices who come together to learn from one another, and the library plays a primary role in offering the tools and education to get started, as well as the opportunity to build relationships that help a digital scholar accomplish their goals.

\section{Acknowledgments}

We would like to extend our thanks to the 2016-17 ACRL Digital Scholarship Centers Interest Group Conveners, Meris Mandernach (Ohio State University), and Jean Ferguson (University of CaliforniaBerkeley).

\section{Notes}

1. Cinthia Ippoliti et al., "ACRL Digital Scholarship Centers Interest Group, Survey of Digital Scholarship Centers Final Report," March 11, 2016, https://drive.google.com/ file/d/0B6OjJzCOmpfudDNzVG1vTUE3ck0/ view.

2. Diane Goldenberg-Hart, "Report of a CNI-ARL Workshop: Planning a Digital Scholarship Center 2016," Washington, DC: Coalition for Networked Information, 2016, https:// www.cni.org/wp-content/uploads/2016/08/ report-DSCW16.pdf.

3. Cinthia Ippoliti et al., "ACRL Digital Scholarship Centers Interest Group."

4. Brian Sinclair, "The University Library as Incubator for Digital Scholarship," Educause Review, June 30, 2016, http://er.educause. edu/articles/2014/6/the-university-library-asincubator-for-digital-scholarship.

5. Jeannette Ekstrøm et al., "The research librarian of the future: data scientist and coinvestigator," The Impact Blog, December 14, 2016, http://blogs.lse.ac.uk/impactofsocialsciences/2016/12/14/the-researchlibrarian-of-the-future-data-scientist-and-coinvestigator/.

6. See the Savvy Researcher workshop series: www.library.illinois.edu/sc/.

7. For more on this idea: http://arielwaldman.com/2014/02/13/adults-are-the-future/. 2 2 